\title{
Closed loop Buck \& Boost Converter Mathematical Modeling, Analysis and Simulation using MATLAB
}

\author{
Farha Naz
}

\begin{abstract}
This article presents the converter circuit analysis, mathematical modeling followed by deriving its average state space equations. The model so obtained is simulated in MATLAB in open loop and closed loop configuration and changes in the output are observed. Specifically, Buck \& Boost converters with \& without its controller at steady state and study of their transient responses to the changing inputs with a controller design and its implementation on SIMULINK model is presented here. The method used to control the output of the converter is Proportional and Integral error correction that is a PI controller which is used to reduce errors and stabilize the variable input fed to the Buck or Boost converters. The tool used to design the controller parameters is PID Tuner application in in MATLAB. The analyses plots derived using the tool lets us examine the controller performance in time and frequency domain. The advantage of the tool used is, it allows user to interactively refine the performance of the controller to adjust loop bandwidth and phase margin or to favor a set-point tracking or disturbance rejection. The designed converters are analyzed in current mode control and voltage mode control to switch on/off. The long term goal is to have a sophisticated controller design for buck \& boost converters for the application where variable input is fed to them, so as to allow its simulation to fully understand how the converters behave when controller is implemented. The model tested here are of the similar nature that are being used in standalone solar or wind energy generation \& distribution systems. The variable nature of the input tested here with Buck \& Boost converters reflects the variable nature of the output of the renewable energy sources and that broaden the scope of these converters to be implanted with such standalone energy systems.
\end{abstract}

Keywords: Boost Converter, Buck converter, Current Control Mode, Voltage Control Mode

\section{INTRODUCTION}

The voltage-mode controlled regulator, the PWM signal is generated by applying a control voltage to one comparator input and a saw-tooth voltage of fixed frequency, generated by the clock, to the other. The duty cycle of the PWM signal is proportional to the control voltage and determines the percentage of the time that the switching element conducts. The control voltage is derived from the difference between the actual-output voltage and the desired-output voltage. [1]

Manuscript received on April 21, 2021.

Revised Manuscript received on April 29, 2021.

Manuscript published on April 30, 2021.

* Correspondence Author

Farha Naz*, Department of Electrical Engineering, SVKM's Institute of Technology, Dhule, Maharashtra, India. Email: farha.naz@svkm.ac.in

(C) The Authors. Published by Blue Eyes Intelligence Engineering and Sciences Publication (BEIESP). This is an open access article under the CC BY-NC-ND license (http://creativecommons.org/licenses/by-nc-nd/4.0/)
The more efficient control scheme that finds a wide application is current mode control. In this type of control the Inductor current is used as a feedback state. The current-mode control technique derives the PWM ramp by adding a second loop feeding back the inductor current. This feedback signal comprises two parts: the AC-ripple current, and the DC or average value of the inductor current. An amplified form of the signal is routed to one input of the PWM comparator while the error voltage forms the other input. It will generate PWM pulses, which will act as a controlling signal to the power electronic devices. [14] The advantage is the ease to control and integrate. The voltage transformation in dc-dc converter is achieved by using the technique of PWM (pulse width modulation). The power needed for pulse train is very small and can be neglected.

There are different combinations of switching devices using different energy storing elements used as switching regulators. These switching regulators convert the unregulated dc input to an accurate and desired dc output voltage. Based on the control and regulation of the voltage/current at the output terminals from an input source, the switching regulators can be divided as: Isolated \& Non-isolated converters. [2] The transfer of the energy from the input to the output side is done using electromagnetic field. This can be achieved using a mutually coupled magnetic component thereby isolating the input and the output. So this type of DC-DC converter cannot be used where it is desired to have the ground terminal of input and output at different potentials (for example, in case of gate drive circuit of an inverter's devices). Also, if the transformation ratio between the input \& output voltage is too large/low, the on-time/off-time of the device becomes comparable to the device turn-on/turn-off time. Therefore, in such cases, isolated type DC-DC converters are more advantageous. There is no isolation in between the input and the output, i.e. the current flows through a common path during the operation from the source to the load. The selection of converters from a variety of switching system available in the market is based on certain parameters (cost, performance, characteristics) which are determined by the user and the system application. [3]

This paper will limit its consideration to the first two types of non-isolated converters (Buck \& Boost). This paper presents the converter circuit analysis,

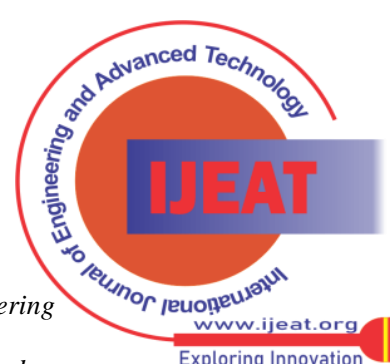


mathematical modeling followed by deriving its average state space equations. The model so obtained is simulated in MATLAB in open loop and closed loop configuration and changes in the output is observed. PI controller is used here to reduce the errors. These DC-to-DC power converters steps up/down the voltage (while stepping down/up the current) from its input (supply) to its output (load). The DC input to a buck or boost converter can be from many sources as well as batteries, such as rectified AC from the supply mains, or DC from solar panels, fuel cells, dynamos and DC generators.

\section{MODELING OF BUCK \& BOOST CONVERTER}

\section{A. Buck or Step-Down converter}

In the step-down or buck converter, average dc output voltage $V_{o}$ is less than the input unregulated dc voltage $V_{s}$. Thus, it is a voltage step-down and current step-up converter. A simplified circuit diagram is shown in figure below.

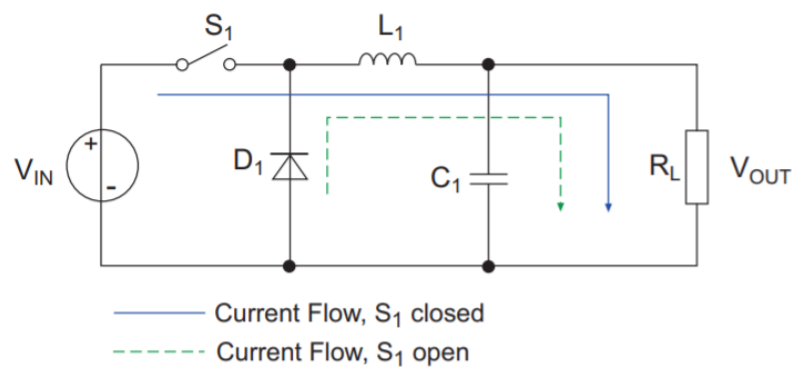

Fig.1 Buck Converter [13]

The transfer function for the buck converter is derived by equating the voltage-time product of the inductance in the $\mathrm{ON}$ and OFF conditions. The products so obtained for ON and OFF conditions must be the same because of the energy conservation principle.

Energy equations during ON condition: $\mathrm{E}_{\mathrm{IN}}=\left(\mathrm{V}_{\mathrm{IN}}-\mathrm{V}_{\mathrm{OUT}}\right) \mathrm{t}_{\mathrm{ON}}$ Energy equations during OFF condition: $\mathrm{E}_{\mathrm{OUT}}=\mathrm{V}_{\mathrm{OUT}} \mathrm{t}_{\mathrm{OFF}}$

$$
\delta=\frac{\text { ton }}{T}=\frac{\text { ton }}{\text { ton }+ \text { toff }}
$$

Using above equation,

$$
\begin{gathered}
\left(V_{I N}-V_{\text {OUT }}\right) t_{\text {ON }}=V_{\text {OUT }}\left(T-t_{\text {ON }}\right) \\
V_{\text {IN }} t_{\text {ON }}=V_{\text {OUT }} T \\
\text { Vout }=\text { Vin } \frac{\text { ton }}{T}=\delta \text { Vin }
\end{gathered}
$$

\section{a) Voltage Control Mode}

The controller manipulates the error term depending on the type of controller that is being used. The output of the controller is the new value of the duty cycle which is used as an input to the power stage and modulates the switching devices so as to close the control loop and provide a regulated and stable output voltage. [5]

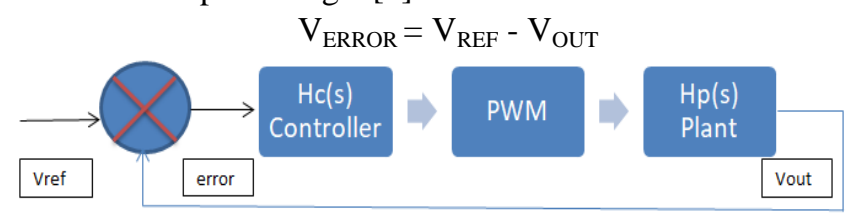

Fig.2 Buck Converter voltage control loop

The transfer functions of the LC filter:

Published By:

Blue Eyes Intelligence Engineering and Sciences Publication

$$
\begin{gathered}
\mathrm{H}(\mathrm{s})=\frac{1}{\frac{s^{2}}{\omega L C^{2}}+s \frac{1}{Q \omega L C}+1} \\
\omega L C=\frac{1}{\sqrt{L C}} \\
Q=\frac{1}{2 \varepsilon}=R \sqrt{\frac{C}{L}}
\end{gathered}
$$

\section{b) Current Control Mode}

In this type of control the peak of the output filter inductor current is controlled to a set point value. This set point value is determined by the output of the controller and varies on a cycle-by-cycle basis.

Initially, the switching device is turned on with no pre-determined duty cycle given by the clock pulse which sets the S-R latch. The sensed inductor current is then compared with the desired current by means of a current comparator. When the sensed inductor current intersects with the desired current, the current sense comparator resets the S-R latch, which turns off the switching device.

Therefore, the duty cycle is not set by the controller and is determined by the rise of the inductor current during the on-time. The modulation of the duty cycle differs significantly from that of voltage mode control, and as such, the design of the compensator differs also.

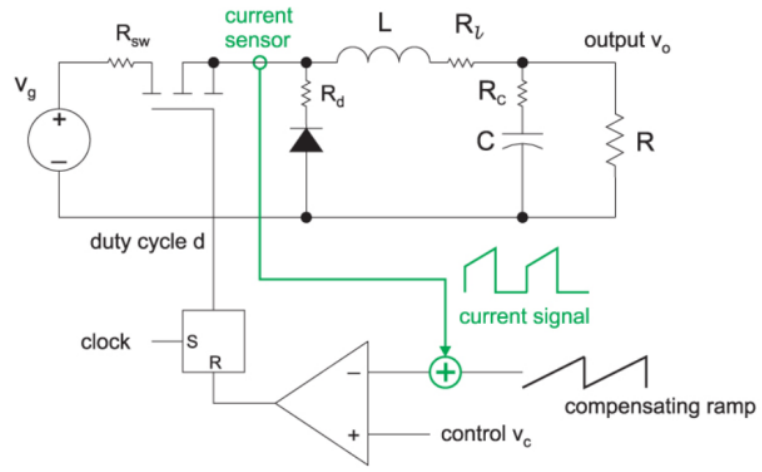

Fig.3 Buck Converter current control loop [1] The DC gain for the current mode buck converter is:

$$
\begin{gathered}
H_{D C}=\frac{R_{0}}{R_{1}} \cdot \frac{1}{1+\frac{R_{0} T_{s}}{L_{0}}\left(m_{c}(1-D)-0.5\right)} \\
H_{p}(\mathrm{~s})=\frac{1}{1+\frac{s}{\omega P_{1}}} \\
\omega P_{1}=\frac{1}{R_{0} C_{0}}\left(\frac{T_{s}}{L_{0} C_{0}}\left(m_{c}(1-D)-0.5\right)\right)
\end{gathered}
$$

The power stage output filter consists of an inductor and a capacitor that normally forms a double pole due to resonance formed between the inductor and capacitor. In current mode control, the inductor's current is controlled on a cycle-by-cycle basis, and therefore the inductor acts as a constant current source.

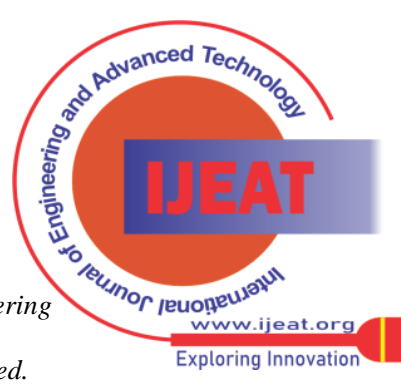


This implies that the plant power stage no longer contains the double pole present when operating under voltage mode control and the plant power stage now only contains a single plant pole. This control method results in a single plant pole at lower frequencies. This removes the crossover frequency restriction around the double pole found in voltage-mode controlled converters and therefore allows for easier stabilizing of converters with a right-half plane zero.

\section{B. Boost or Step-Up Converter}

In the step-up or boost converter, average dc output voltage $\mathrm{V}_{\mathrm{o}}$ is more than the input unregulated dc voltage $\mathrm{V}_{\mathrm{s}}$. Thus, it is a voltage step-up and current step-down converter. A simplified circuit diagram is shown in figure below. [3]

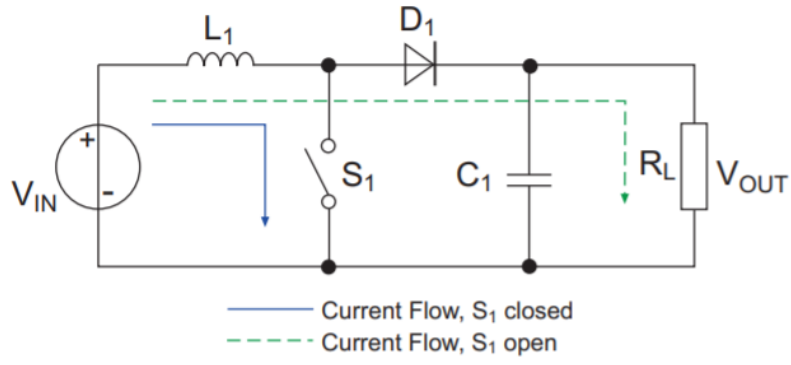

Fig.4 Boost Converter [13]

The transfer function for the boost converter is derived by equating the voltage-time product of the inductance in the ON and OFF conditions. The products so obtained for ON and OFF conditions must be the same because of the energy conservation principle.

Energy equations during ON condition: $E_{I N}=V_{\text {IN }} t_{\mathrm{ON}}$ Energy equations during OFF condition: $\mathrm{E}_{\mathrm{OUT}}=\left(\mathrm{V}_{\mathrm{OUT}}-\mathrm{V}_{\mathrm{IN}}\right) \mathrm{t}_{\mathrm{OFF}}$

$$
\delta=\frac{\text { ton }}{T}=\frac{\text { ton }}{\text { ton }+ \text { toff }}
$$

Using above equation,

$$
\frac{\text { Vout }}{\text { Vin }}=\frac{1}{1-\delta}
$$

\section{a) Voltage control mode}

Voltage-mode control which is also called as the duty-cycle control contains a single loop and adjusts the duty cycle directly in response to changes in output voltage.

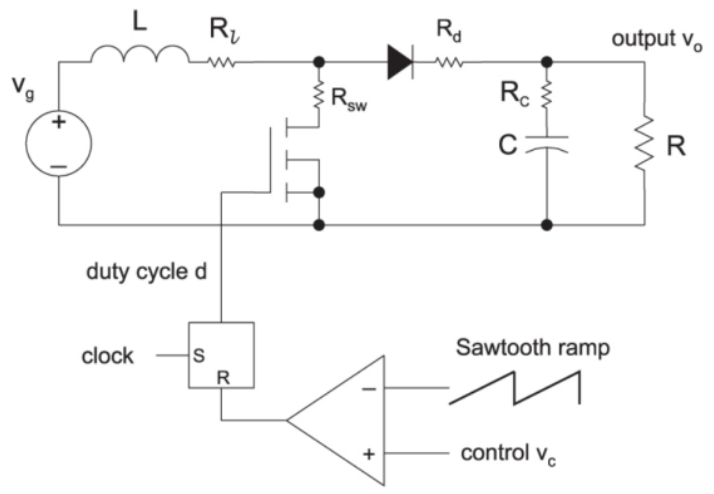

Fig.5 Boost Converter voltage control mode [1]

The equation for the control-to-output transfer function is:

$$
\begin{gathered}
\frac{\widehat{v_{0}}}{\widehat{d}}=\frac{V_{g}}{D^{2}} \times \frac{\left(1+s C R_{c}\right) \times\left(1-s \frac{L_{e}}{R_{L}}\right)}{1+\frac{s}{\omega_{0} Q}+\frac{s^{2}}{\omega_{0}^{2}}} \\
\omega_{0}=\frac{1}{\sqrt{(L C)}}
\end{gathered}
$$

The boost converter adds a new complexity to the control problem which is caused by the fact that when the boost converter switch is turned on for a longer period of time, the inductor is disconnected from the load for a longer period of time which makes the output initially drop, even though the control command is trying to make it increase.

\section{b) Current control mode}

Current-mode control which is also called as current programmed mode or current-injected control is a multiple-loop control method that contains two loops (an inner current loop and an outer voltage loop). There are several types of current mode control methods, and the most popular method is fixed-frequency peak-current-mode control with fixed-slope compensation ramp. The technique is called current-mode control because the inductor current is directly controlled, whereas the output voltage is controlled indirectly by the current loop. [4] A control reference is used to regulate the peak current of the converter directly. Figure shows the schematic of the boost converter with current-mode control:

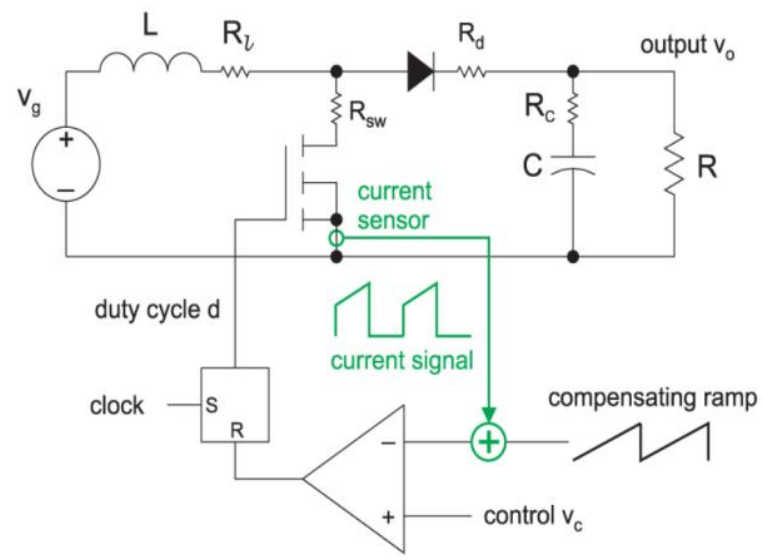

Fig.6 Boost Converter current control mode [1]

\section{Inductor and Capacitor behavior}

The basic concept of operation is that every time the switch is closed, current builds up in the inductor. When the switch is opened, the current can't stop instantly and so it's forced to flow into the capacitor until the current dissipates. If the switch is closed again, the diode ensures that the capacitor won't discharge back through the switch. This process of opening and closing the switch can be repeated many times with each cycle adding more charge onto the capacitor until a limiting value of voltage is attained.

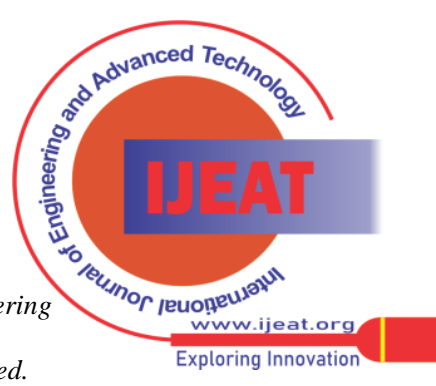




\section{a) Inductor property}

Inductor stores energy in the form of magnetic field, and electric current is responsible for it. Therefore electric current flowing through the inductor cannot change suddenly. An applied voltage will cause current through the inductor to build up over time at a rate inversely proportional to its inductance $\left(\mathrm{L}_{1}\right)$. That process is governed by the equation:

$$
v(t)=L 1 \frac{d i(t)}{d t}
$$

A MATLAB code was developed which simulates the behaviour and makes the plot with the title "Initialization Period" which is given in figure. It can be seen that with the components chosen, the whole initialization process is in less than $1 / 100^{\text {th }}$ of a second, so one may not be able to observe it easily without a storage scope. To reach $99 \%$ of the steady state current took just about 5 milliseconds.

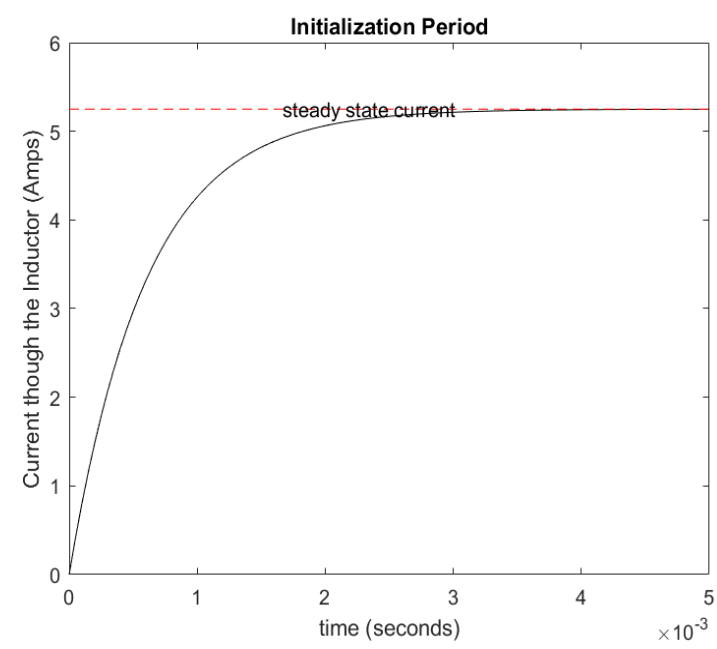

Fig.7 Initialization period (Inductor Current)

$$
\begin{gathered}
V_{I N}=i R+L 1 \frac{d i}{d t} \\
i(t)=\frac{V_{d c}}{R}\left(1-e^{-\frac{t}{\tau}}\right) \\
\text { where } \tau=\frac{L 1}{R} \\
\text { Inductor Ripple Current } \Delta I_{L}=\frac{\left(V_{I N(\max )-V_{O U T}}\right) \times D}{f_{S} \times L}
\end{gathered}
$$

Table.1 Instantaneous current at various times

\begin{tabular}{|c|c|}
\hline Time & Instantaneous Current \\
\hline For $=0 \tau$ & $i(t)=0$ \\
\hline For $=1 \tau$ & $i(t)=0.63 \frac{V_{d c}}{R}$ \\
\hline For $=2 \tau$ & $i(t)=0.86 \frac{V_{d c}}{R}$ \\
\hline For $=3 \tau$ & $i(t)=0.95 \frac{V_{d c}}{R}$ \\
\hline For $=4 \tau$ & $i(t)=0.98 \frac{V_{d c}}{R}$ \\
\hline
\end{tabular}

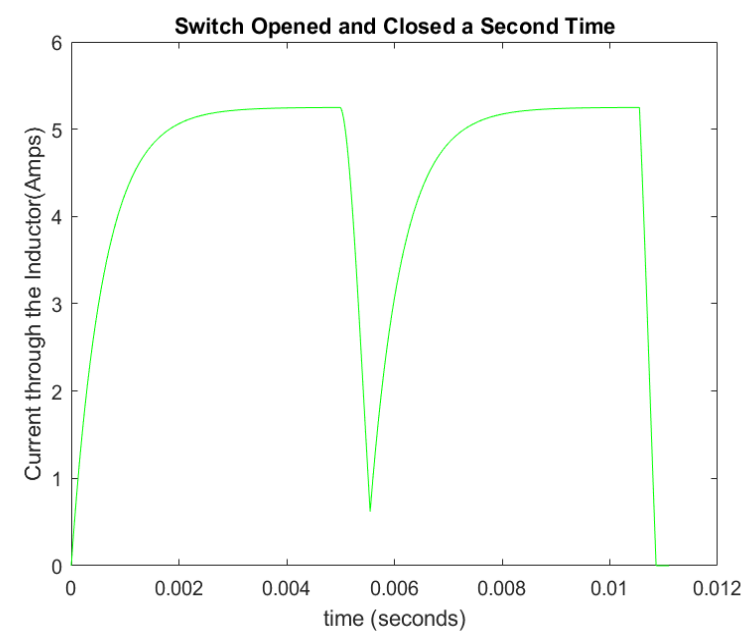

Fig.8 Inductor current in two cycles

We can find the recommended inductor values in a datasheet. An inductor is chosen from this range. The higher the value of $\mathrm{L}$, the higher is the maximum output current because of the reduced ripple current. In general, the lower the inductor value, the smaller is the solution size. The inductor must always have a higher current rating than the maximum current because as the current increases the inductance decreases. If no inductor range is provided, the following equation is a good estimation for the right inductor:

$$
L=\frac{V_{\text {OUT }} \times\left(V_{I N}-V_{\text {oUT }}\right)}{\Delta I_{L} \times f_{S} \times V_{I N}}
$$

A good estimation for the inductor ripple current is $20 \%$ to $40 \%$ of the output current.

\section{b) Capacitor property}

Capacitor stores energy in the form of electric field, and voltage across it, is responsible for the stored energy. Therefore voltage across capacitor cannot change suddenly. Now let's say that after letting the system initialize with the switch closed (ON), the switch is now opened (OFF). The capacitor becomes important at this stage because the only possible path for the current to flow is forward through the diode and into the capacitor. Voltage across the capacitor will build up over time at a rate proportional to the current and inversely proportional to the capacitance $\left(\mathrm{C}_{1}\right)$

With the help of a voltmeter, the voltage across the capacitor is measured so that one can track the behaviour of the capacitor as the voltage changes. Note that voltmeter actually allows some current to flow. We usually can neglect this, but here in this case, it is considered as it is to be modelled. Let's say the voltmeter acts like a resistor with fixed resistance of $\mathrm{R}_{\text {load. }}$

A MATLAB code was developed that simulates the circuit's behaviour and makes another plot which is entitled "Switch Opened after Initialization Period".

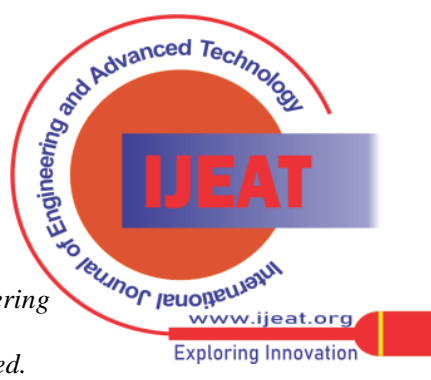




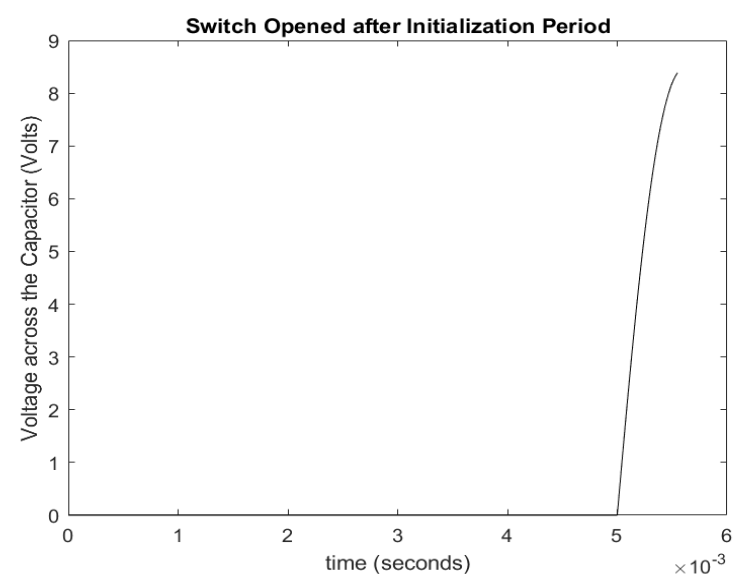

Fig.9 Capacitor voltage

Given the components chosen, the build-up of voltage happens even faster than the build-up of current did in the previous phase. The time constant should be resistance multiplied by capacitance, meaning the resistance of the inductor at 0.5 ohms times the capacitance of 220 micro-Farads. The "micro" part is essential here! That's just about 0.1 milliseconds for a time constant. And note the highest electric potential attained across the capacitor was about $8 \mathrm{~V}$, as shown in the simulation result in figure. One could guess that, by assuming that the energy built up in the inductor was converted efficiently to energy in the capacitor. That would imply:

$$
\frac{1}{2} C 1 V^{2}=\frac{1}{2} L 1 I^{2}
$$

So rearranging gives,

$$
V=\sqrt{\frac{L 1}{C 1} I}
$$

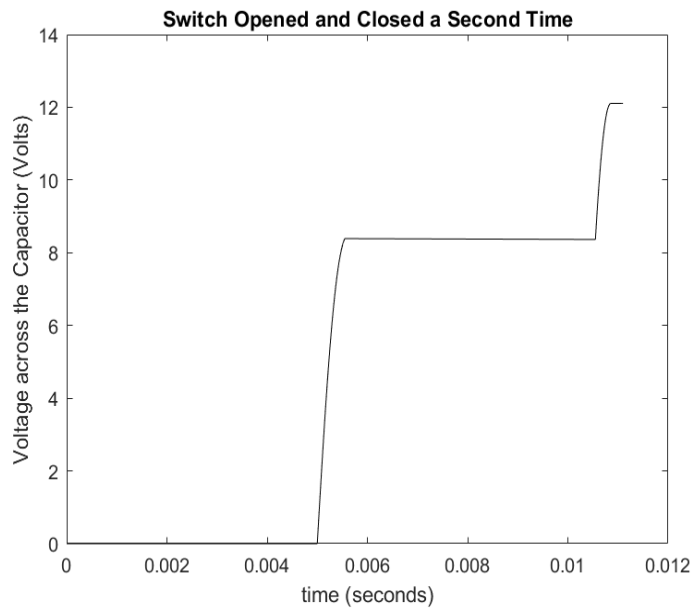

Fig.10 Capacitor voltage in second cycle

The current in the inductor when the switch is closed was about 5 Amps, so the change in voltage would be predicted from conservation of energy to be 8 Volts. The Voltage reached $99 \%$ of that steady state value in 1 millisecond. The voltage build up was about 5 times faster than the current build up. When switch is closed, by using KCL we will have:

$$
\begin{gathered}
i_{c}=\frac{V_{R}}{R}+C 1 \frac{d v}{d t} \\
v(t)=i_{c} R\left(1-e^{-\frac{t}{\tau}}\right) \\
\text { where, } \tau=R C 1
\end{gathered}
$$

Table.2 Instantaneous current at various times

\begin{tabular}{|c|c|}
\hline Time & Capacitor Current \\
\hline For $=0 \tau$ & $i(t)=0$ \\
\hline For $=1 \tau$ & $i(t)=0.63 V_{c}$ \\
\hline For $=2 \tau$ & $i(t)=0.86 V_{c}$ \\
\hline For $=3 \tau$ & $i(t)=0.95 V_{c}$ \\
\hline For $=4 \tau$ & $i(t)=0.98 V_{c}$ \\
\hline
\end{tabular}

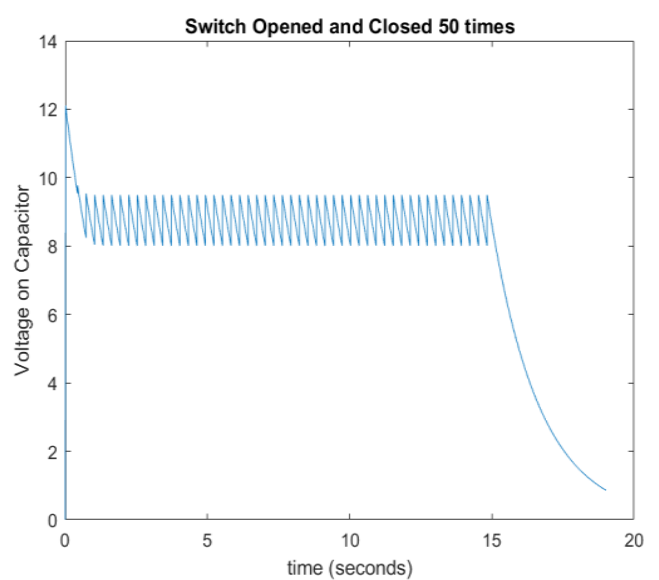

Fig.11 Capacitor voltage in 50 cycles

The minimum value for the input capacitor is normally provided in the data sheet. This minimum value is necessary to stabilize the input voltage due to the peak current requirement of the switching power supply. Low-equivalent series resistance (ESR) can be used. The value can be increased if the input voltage is noisy

\section{State Space equations}

Assuming that all components are ideal, that is no internal resistance in the circuit and the circuit components that don't consume any energy. By following the averaging method to derive the following:

a) Boost Converter

When switch is closed -

$$
\left[\begin{array}{l}
\dot{x}_{1} \\
\dot{x}_{2}
\end{array}\right]=\left[\begin{array}{cc}
0 & 0 \\
0 & -\frac{1}{R C}
\end{array}\right]\left[\begin{array}{l}
x_{1} \\
x_{2}
\end{array}\right]+\left[\begin{array}{l}
\frac{1}{L} \\
0
\end{array}\right] V_{\text {in }} \quad \text { i.e e. } \dot{x}_{1}=A_{1} x+B_{1} u
$$

When switch is open -

$$
\left[\begin{array}{l}
\dot{x}_{1} \\
\dot{x}_{2}
\end{array}\right]=\left[\begin{array}{cc}
0 & -\frac{1}{L} \\
\frac{1}{C} & -\frac{1}{R C}
\end{array}\right]\left[\begin{array}{l}
x_{1} \\
x_{2}
\end{array}\right]+\left[\begin{array}{l}
\frac{1}{L} \\
L
\end{array}\right] V_{\text {in }} \text { i.e. } \dot{x}_{1}=A_{2} x+B_{2} u
$$

Averaging the state space matrix of two different working modes, we get the average model.

$$
\dot{x}=\left[\begin{array}{cc}
0 & -\frac{(1-d)}{L} \\
\frac{(1-d)}{C} & -\frac{1}{R C}
\end{array}\right] x+\left[\begin{array}{c}
\frac{1}{L} \\
0
\end{array}\right] V_{\text {in }}
$$

Published By:

Blue Eyes Intelligence Engineering and Sciences Publication

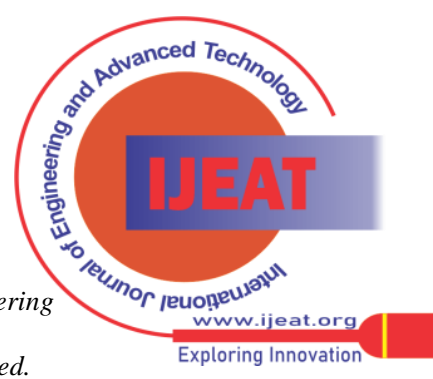




$$
\text { Where, } \quad \bar{A}=\left[\begin{array}{cc}
0 & -\frac{(1-d)}{L} \\
\frac{(1-d)}{C} & -\frac{1}{R C}
\end{array}\right] \& \bar{B}=\left[\begin{array}{l}
1 \\
L \\
0
\end{array}\right] V_{\text {in }}
$$

\section{b) Buck Converter}

When switch is closed -

$$
\left[\begin{array}{l}
\dot{x}_{1} \\
\dot{x}_{2}
\end{array}\right]=\left[\begin{array}{cc}
0 & -\frac{1}{L} \\
\frac{1}{C} & -\frac{1}{R C}
\end{array}\right]\left[\begin{array}{l}
x_{1} \\
x_{2}
\end{array}\right]+\left[\begin{array}{l}
\frac{1}{L} \\
L
\end{array}\right] V_{\text {in }} \text { i.e e. } \dot{x}_{1}=A_{1} x+B_{1} u
$$

When switch is open -

$$
\left[\begin{array}{l}
\dot{x}_{1} \\
\dot{x}_{2}
\end{array}\right]=\left[\begin{array}{cc}
0 & -\frac{1}{L} \\
\frac{1}{C} & -\frac{1}{R C}
\end{array}\right]\left[\begin{array}{l}
x_{1} \\
x_{2}
\end{array}\right]+\left[\begin{array}{l}
0 \\
0
\end{array}\right] V_{\text {in }} \text { i. e. } \dot{x}_{1}=A_{2} x+B_{2} u
$$

Averaging the state space matrix of two different working modes, we get the average model.

$$
\begin{array}{cl}
\dot{x}=\left[\begin{array}{ll}
0 & -\frac{1}{L} \\
\frac{1}{C} & -\frac{1}{R C}
\end{array}\right] x+\left[\begin{array}{l}
\frac{d}{L} \\
0
\end{array}\right] V_{\text {in }} \\
\text { Where, } \quad \bar{A}=\left[\begin{array}{ll}
0 & -\frac{1}{L} \\
\frac{1}{C} & -\frac{1}{R C}
\end{array}\right] \& \bar{B}=\left[\begin{array}{l}
\frac{d}{L} \\
0
\end{array}\right] V_{\text {in }}
\end{array}
$$

\section{E. Flow diagram}

If all the parameters are designed, the calculation of the power stage can take place which can be realized with the procedure given in below:

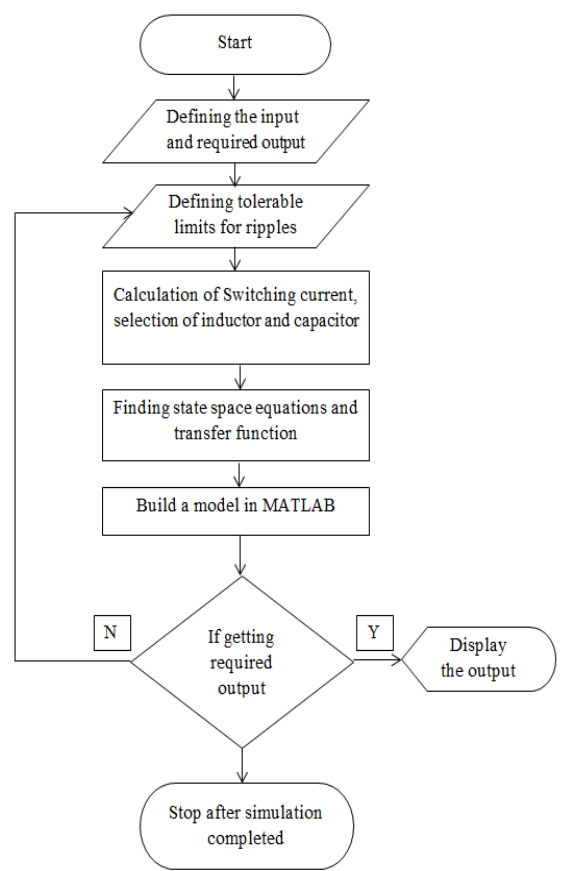

Fig.12 Flowchart for modeling of the converter

\section{CONTROLLER DESIGN}

A PI controller for a given system is designed; following steps are to be followed to obtain a desired response and the procedure to design is given the figure below:

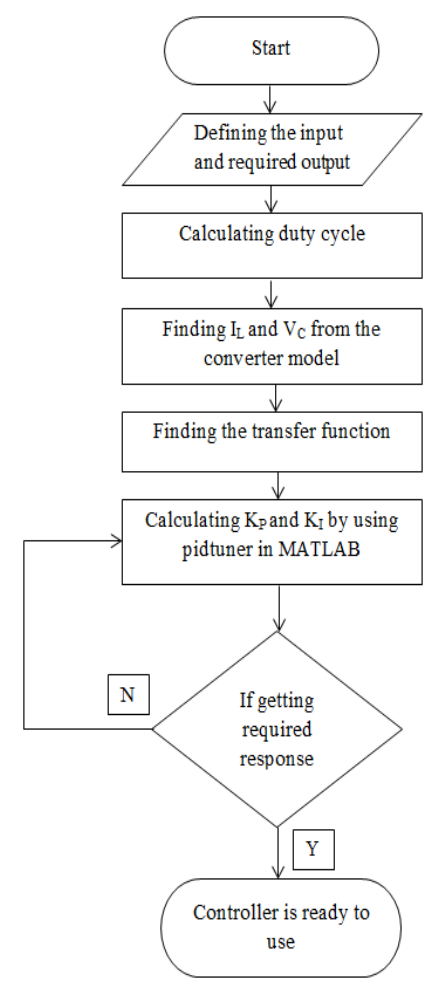

Fig.13 Flowchart for converter design

1. Obtain an open-loop response and determine what needs to be improved

2. Add a proportional control to improve the rise time

3. Add a derivative control to improve the overshoot

4. Add an integral control to eliminate the steady-state error

5. Adjust each of $\mathrm{K}_{\mathrm{p}}, \mathrm{K}_{\mathrm{i}}$, and $\mathrm{K}_{\mathrm{d}}$ until a desired overal response is reached.

An integral controller (Ki) decreases the rise time, increases both the overshoot and the settling time, and eliminates the steady-state error. For the given system, the closed-loop transfer function with a PI control is:

$$
\begin{gathered}
\frac{X(s)}{F(s)}=\frac{K_{P} s+K_{i}}{s^{3}+10 s^{2}+\left(20+K_{P} s+K_{i}\right)} \\
C(s)=K_{P}+K_{i} \times \frac{1}{s}
\end{gathered}
$$

Here, the proportional gain $\left(\mathrm{K}_{\mathrm{p}}\right)$ is reduced because the integral controller also reduces the rise time and increases the overshoot as the proportional controller does (double effect).

The frequency response for the boost converter with current mode control is shown in figure 5.7. The duty cycle with switching frequency $20 \mathrm{kHz}$ is varied from the 0.333 to 0.78 to observe the transient in inductor current of Boost Converter with current control mode. The values of $\mathrm{K}_{\mathrm{p}}$ and $\mathrm{K}_{\mathrm{i}}$ are taken as 0.87 and 457 respectively, obtained from the following transfer functions. With similar method, PI parameters are derived for buck converter. A MATLAB code was developed to obtain the transfer function given below:

$$
\mathrm{TF}=\frac{0.2798 \mathrm{~s}+5.061}{0.0002764 \mathrm{~s}^{2}+0.001045 \mathrm{~s}+0.2253}
$$

Published By:

Blue Eyes Intelligence Engineering and Sciences Publication

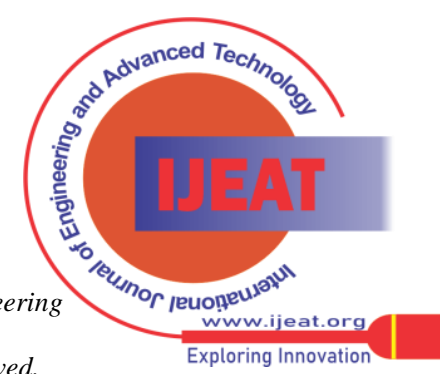


Crossover frequency obtained from the above transfer function for Boost converter in current control mode by drawing frequency response plot with help of MATLAB code, is $975 \mathrm{rad} / \mathrm{s}$.

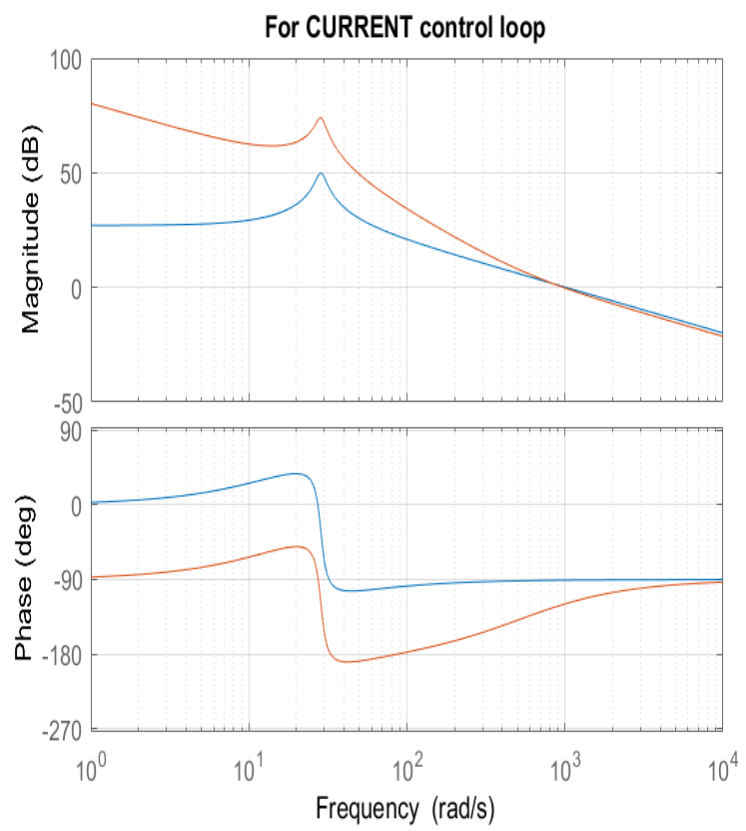

Fig.14 Effect of input voltage variation on the Control Characteristic of the Boost Converter

The boost converter also has a resonant frequency which changes with the input voltage as is shown in the control equations. Above figure shows graphically how the characteristics of the boost converter can vary dramatically with a wide input voltage.

\section{SIMULATION \& ANALYSIS}

\section{A. Buck Converter}

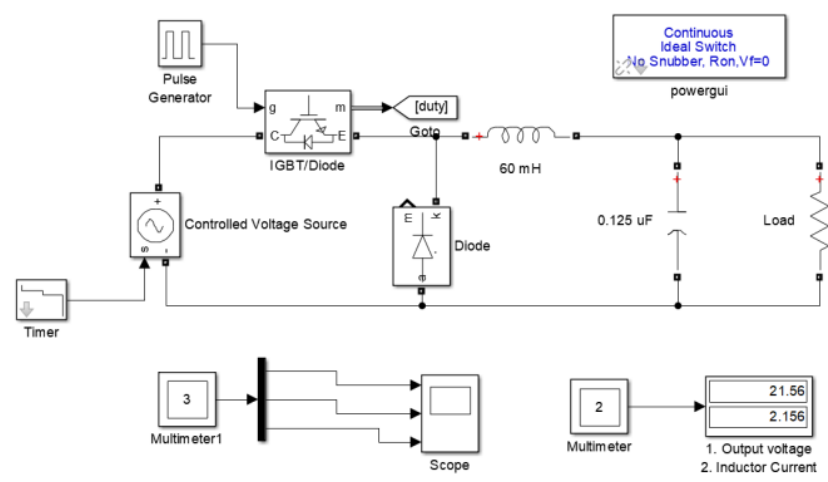

Fig.15 Buck Convertor - open loop

The inductor current and output voltages has ripples which are not in tolerable limit, it is approximately more than $10 \%$ of the average value of the quantity. It can be seen in figure given below:

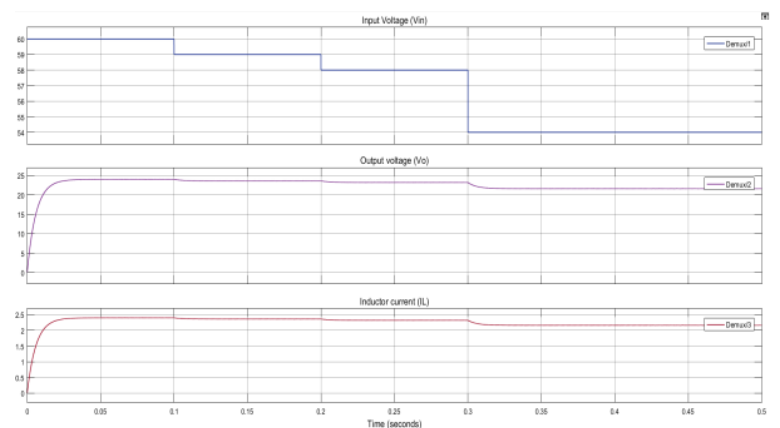

Fig.16 Simulation results for Buck Converter in Open loop with variable input

What is desirable is to have regulated constant output which is within the tolerable limit, for inductor current and output voltage it is $5 \%$ to $10 \%$. To prevent the output from increasing or decreasing in the multiple (here multiplication factor is duty cycle), duty cycle must be changed whenever input supply changes. It can be done by varying PWM pulses with the help of a controller and to reduce ripples a filter is required.

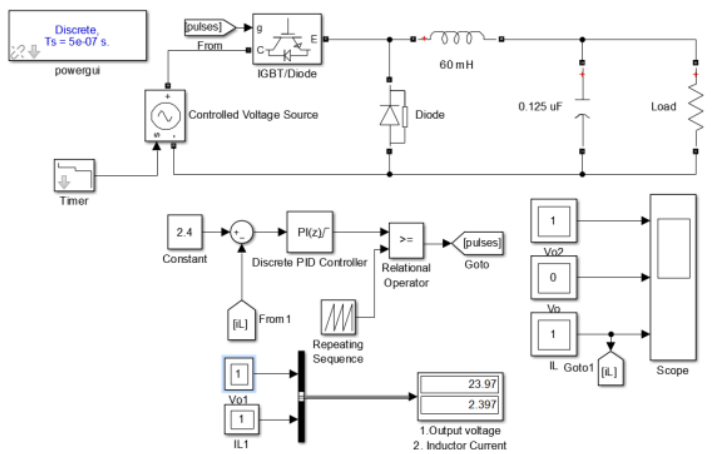

Fig.17 Buck Convertor - Closed loop

If the input voltage is variable in nature a controller is designed which will reduce ripples as well as give regulated and required output when input is variable. The figure 18 shows results for buck converter with constant input in closed after designing a controller. It can be said after observing the above figure that the output voltage is constant at $24 \mathrm{~V}$ and ripples in inductor current are less than 5\%, which are in tolerable limits. Also, it has been observed from the simulation result that the PI controller can get zero tracking error, and is proper for voltage control.

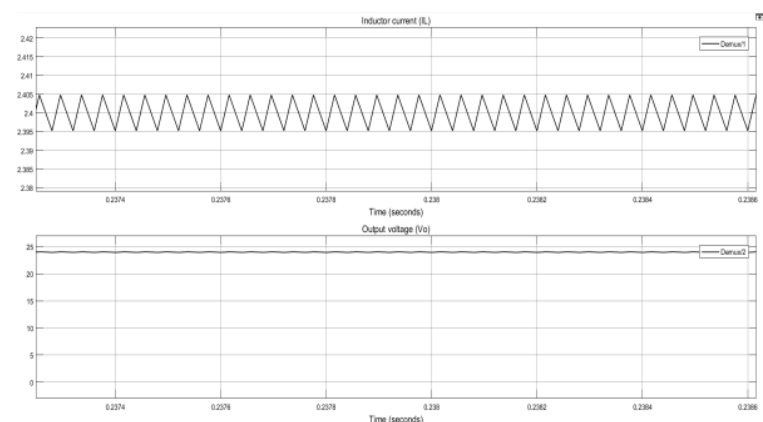

Fig.18 Simulation results for Buck Converter in Closed loop with Constant input

Published By:

Blue Eyes Intelligence Engineering and Sciences Publication

(C) Copyright: All rights reserved. 
Results for Buck Converter in Closed loop with variable input are given in figure 19. When the figure is compared with figure 18 , it can be concluded that with the variable input voltage supply, the resulting output voltage remains constant.
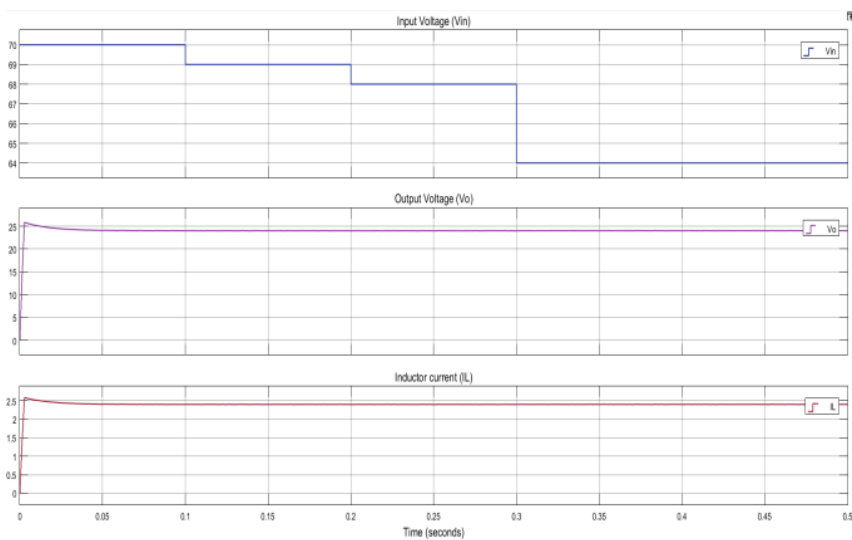

Fig.19 Simulation results for Buck Converter in Closed loop with variable input

\section{B. Boost Converter}

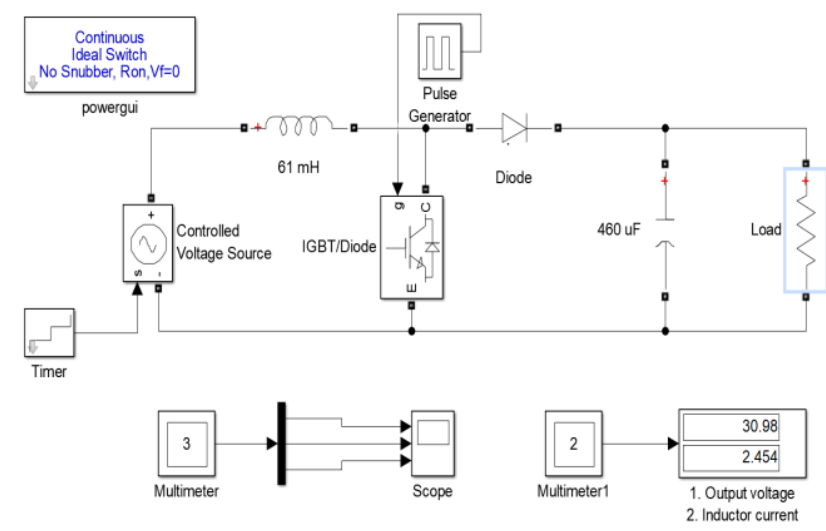

Fig.20 Boost Convertor - open loop

Results obtained for boost converter for open loop with variable input is shown below in figure 21 in which the output voltage is varying with the variation in input voltage. The large variations can be seen in output of the boost converter with lesser variations in input variations.
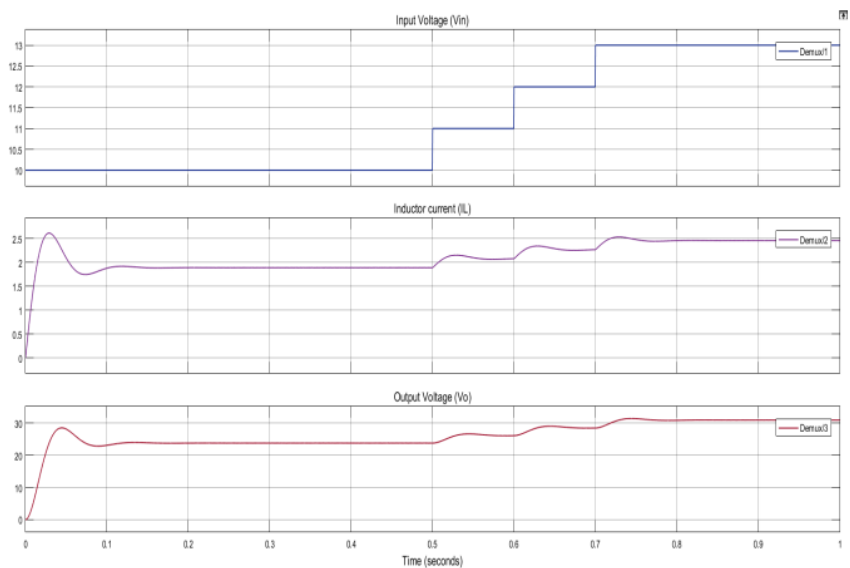

Fig.21 Simulation results for Boost Converter in Open loop with variable input

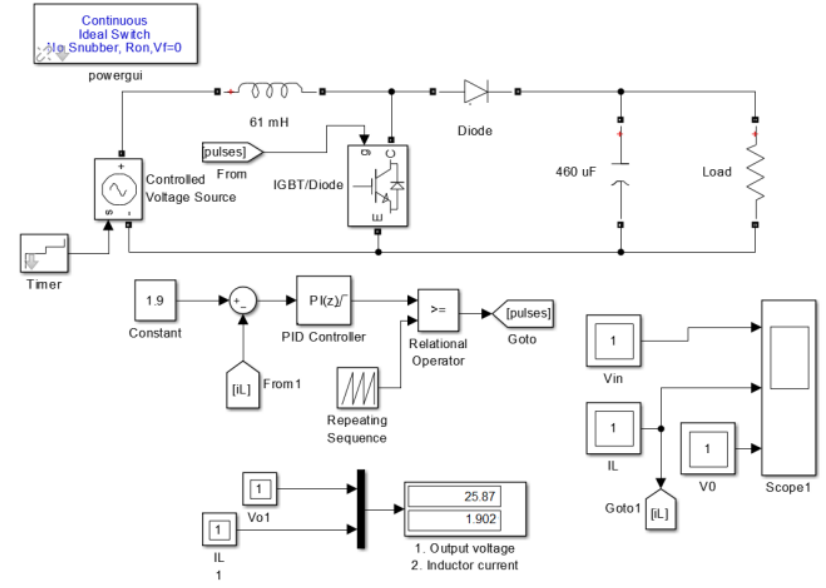

Fig.22 Boost Convertor - Close loop

To have lesser variations in output voltage converter is operated in closed loop with a controller. Figure 24 shows the response of the boost converter in closed loop for variation in input. The variation in output is lesser as compared to the open, it can be said that it almost constant, because it is in tolerable limits.

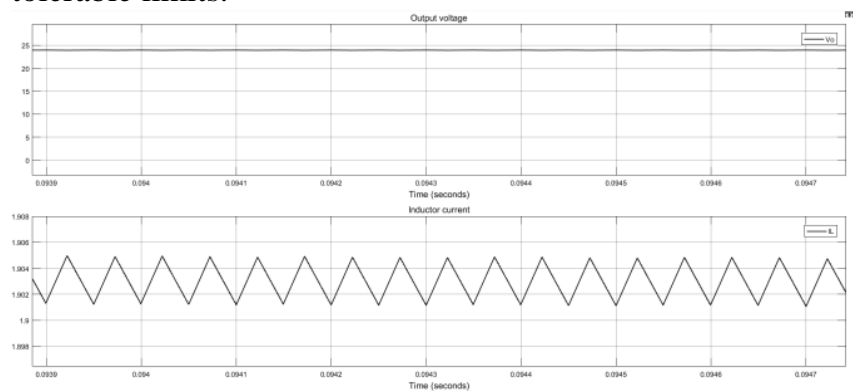

Fig.23 Simulation results for Boost Converter in Closed loop with Constant input

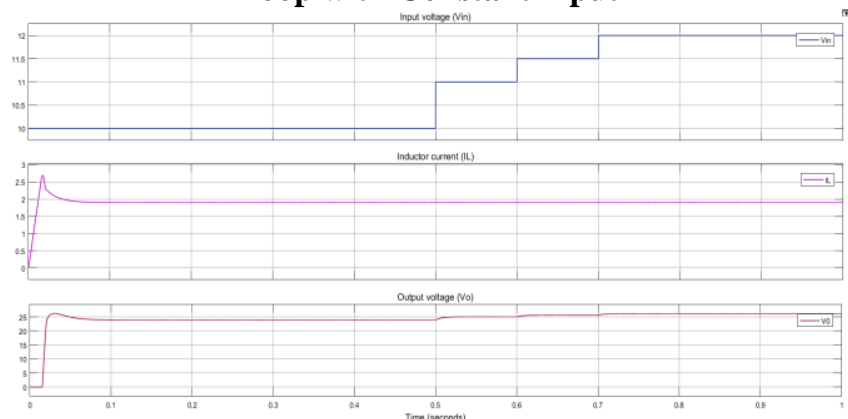

Fig.24 Simulation results for Boost Converter in Closed loop with variable input

\section{CONCLUSION}

The design and simulation of PI controllers for Buck \& Boost converters for constant as well as variable input is successfully tested with the selected and calculated element values for open loop and closed loop. An integral controller (Ki) helped in decreasing the rise time, increasing both the overshoot and the settling time, and eliminating the steady-state error.

Published By:

Blue Eyes Intelligence Engineering

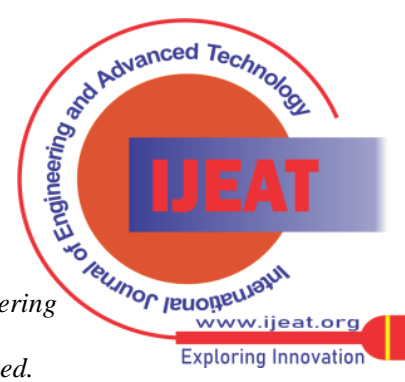


The proportional gain (Kp) was reduced because the integral controller and also reduced the rise time and increased the overshoot as the proportional controller does the double effect. To find the parameter values for PI controller MATLAB provided tools for automatically choosing optimal PID gains which makes the trial and error process smoother and faster. It has been observed from the simulation result that the PI controller can get zero tracking error, and is proper for voltage control.

It can be concluded that with the variable input voltage supply, the resulting output voltage remains constant. The designed model behaves efficiently with below $5 \%$ ripple current under the rapid variations of input voltage as obtained in the MATLAB Simulink model. The converters along with controllers are well designed that such prototypes are implementable in applications such as Microgrid, Standalone solar power control, Standalone Wind power control. It is feasible to use this model with DSP processor for the control operation for various applications like DC distribution system, Microgrid energy management system.

\section{REFERENCES}

1. Barry W. Williams, "Basic DC-to-DC Converters", IEEE Transaction On Power Electronics, vol.23, no.1, pp. 387-401, 2010

2. H. Liu, H. Hu, H. Wu, Y. Xing and I. Batarseh, "Overview of high-step-up coupled-inductor boost converters", IEEE J. Emerg. Sel. Topics Power Electron., vol. 4, no. 2, pp. 689-704, Jun. 2016

3. S. Saravanan and N. R. Babu, "Design and development of single switch high step-up DC-DC converter", IEEE J. Emerg. Sel. Topics Power Electron., vol. 6, no. 2, pp. 855-863, Jun. 2018.

4. A. Sarikhani, B. Allahverdinejad, M. Hamzeh and E. Afjei, "A continuous input and output current quadratic buck-boost converter with positive output voltage for photovoltaic applications", Sol. Energy, vol. 188, pp. 19-27, Aug. 2019

5. A. J. Forsyth, "Modeling and Control of DC-DC Converters," Power Engineering Journal, Vol. 12, No. 5, 1998, pp. 229-236

6. Kirubakaran, "DSP-Controlled Power Electronic Interface for Fuel Cell Based Distributed Generation," in Power Electronics, IEEE Trans. on , vol.26, no.12, pp.3853-3864, Dec. 2011.

7. Belvedere, Bianchi, "A Microcontroller-Based Power Management System for Standalone Micro-grids With Hybrid Power Supply," in Sustainable Energy, IEEE Trans. on , vol.3, no.3, pp. 422-431, July 2012.

8. M. Starke, L. M. Tolbert, and B. Ozpineci, "AC vs. DC distribution: A loss comparison" in Proc. IEEE Conf. and Exhibition on Transmission and Distribution, 2008, pp. 1-7.

9. R. K. Chauhan, B. S. Rajpurohit, "DC grid interconnection for conversion losses and cost optimization”, RIGET, Springer Singapore, 2014, ch.14, pp. 327-345.

10. K. W. E. Cheng, "Overview of the DC power conversion and distribution", Asian Power Electronics J., vol. 2, no. 2, pp. 75-82.

11. R. K. Chauhan, B. S. Rajpurohit, "DC power distribution system for rural applications" in Proc. 8th National Conf. on Indian Energy Sector, 2012, pp. 108-112.

12. R. K. Chauhan, B. S. Rajpurohit, "Voltage Standardization of DC Distribution System for Residential Buildings" JCET, Vol.4, No.3, May 2016.

13. N. Mohan, T.M. Undeland, and W.P. Robbins, "Power Electronics Converters, Applications and Design", 3rd ed. Hoboken, NJ: Jon Wiley and Sons, 2001.

14. J. G. Cho, "High Power Factor Three Phase Rectifier for High Power Density AC/DC Conversion Applications" Power Electronics Research Division Korea, IEEE-1999

15. Mahendra Singh Rajput1, Arun Pachori, Electrical Engineering Department, Jabalpur Engineering College, Jabalpur "Three Phase Twelve Pulse Controlled Rectifier with Reduced Output Current Harmonics Using PI Controller", In press.

16. Aleksandar Prodic, Robert W. Erickson, Colorado Power Electronics Center , University of Colorado at Boulder, "Design and Implementation of a Digital PWM Controller for a High-Frequency Switching DC-DC Power Converter" IECON'01 0-7803-7108-9

\section{AUTHORS PROFILE}

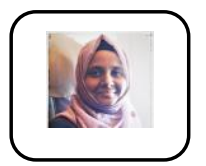

Farha Naz, is an expert in Electrical Power System and has experience of more than 3 years of teaching multiple subjects in this area along with Power Electronics Devices. She has received M.Tech. degree in the specialization of Electrical Power System from Veermata Jijabai Technological Institute (VJTI), Mumbai. She is a top rank holder in both B.Tech. and M.Tech. degree studies. She has authored more than 5 research papers in reputed Journals. She is currently a member of ISTE and IAENG. She has organized several successful online workshops for students and teachers. She is currently working as an Assistant Professor at SVKM's Institute of Technology, Dhule. Her research interests are Optimization of Power Flow, Power Electronics and the use of machine learning techniques in optimal power flow. She is an astute learner and always maintains an upward curve by adapting to new technologies and applying those new technologies for teaching and researching to achieve the sustainable goals. Her research intends to work towards making the use of power electronics device, utilizing renewable energy from micro-grids and shifting towards dc-dc distribution system. She has a good hands-on experience on working with MATLAB Code/ Simulink, Code Composer studio for DSP processor programming.

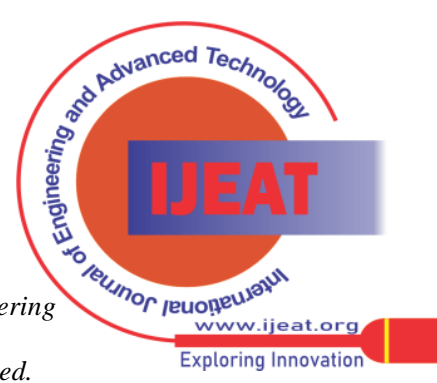

